BMJ Open

Diabetes

Research

\& Care

\title{
Secular incidence trends and effect of population aging on mortality due to type 1 and type 2 diabetes mellitus in China from 1990 to 2019: findings from the Global Burden of Disease Study 2019
}

\author{
Yongze Li (D) , ${ }^{1}$ Chenxi Guo, ${ }^{2}$ Yanli Cao ${ }^{1}$
}

To cite: Li Y, Guo C, Cao Y Secular incidence trends and effect of population aging on mortality due to type 1 and type 2 diabetes mellitus in China from 1990 to 2019: findings from the Global Burden of Disease Study 2019. BMJ Open Diab Res Care 2021;9:e002529. doi:10.1136/ bmjdrc-2021-002529

\section{- Additional supplemental material is published online only. To view, please visit the journal online (http://dx.doi. org/10.1136/bmjdrc-2021- 002529).}

Received 6 August 2021 Accepted 19 0ctober 2021

\section{Check for updates}

C Author(s) (or their employer(s)) 2021. Re-use permitted under CC BY-NC. No commercial re-use. See rights and permissions. Published by BMJ.

For numbered affiliations see end of article.

Correspondence to Professor Yanli Cao; vanilla421@163.com

\section{ABSTRACT}

Introduction Diabetes and population aging have become public health issues of global concern. The secular incidence trends and the impact of population aging on mortality due to type 1 diabetes mellitus (T1DM) and type 2 diabetes mellitus (T2DM) in China remain unclear. Research design and methods The incidence and mortality rates of T1DM and T2DM from 1990 to 2019 were abstracted from the Global Burden of Disease Study (GBD) 2019 database. Joinpoint regression and age-periodcohort models were used to calculate the average annual percentage change and relative risk (RR), respectively. A decomposition method was used to attribute changes in total deaths to population growth, population aging, and the mortality rate change from 1990 to 2019 .

Results From 1990 to 2019, the T1DM age-standardized incidence rate (ASIR) increased by $2.01 \%(95 \% \mathrm{Cl} 1.78 \%$ to $2.23 \%$ ) in males and $1.70 \%(1.61 \%$ to $1.80 \%)$ in females, and the T1DM age-standardized mortality rate (ASMR) decreased by $1.96 \%(-2.22 \%$ to $-1.71 \%)$ in males and $4.02 \%(-4.48 \%$ to $-3.57 \%)$ in females. The T2DM ASIR increased by $0.81 \%(0.62 \%$ to $0.99 \%)$ in males and $0.37 \%$ $(0.16 \%$ to $0.58 \%)$ in females, and the T2DM ASMR increased by $1.06 \%(0.87 \%$ to $1.25 \%)$ in males and decreased by $0.24 \%(-0.54 \%$ to $0.07 \%)$ in females. Compared with 1990 , the proportions of deaths attributed to population aging ranged from $18.85 \%$ (T1DM) to $148.21 \%$ (T2DM) for males and $29.80 \%$ (T1DM) to $118.82 \%$ (T2DM) for females in 2019. Conclusions The T1DM and T2DM incidence rates continually increased in China, particularly among young individuals. T1DM-related mortality decreased, while T2DM-related mortality increased in males. Population aging might be associated with a substantial change in the number of deaths from 1990 to 2019. To address the increase in T2DM-related deaths due to population aging, policymakers should promote aging-related health research and implement proven, cost-effective T2DM interventions.

\section{INTRODUCTION}

Diabetes mellitus has become an epidemic worldwide and in China. According to the

\section{Significance of this study}

What is already known about this subject?

- Previous studies have indicated that the mortality of diabetes decreased in younger age groups but increased in older age groups and that the incidence increased in most age groups in China. Diabetes and population aging have become public health issues of global concern. The secular incidence trends and the impact of population aging on mortality due to specifically type 1 diabetes mellitus (T1DM) and type 2 diabetes mellitus (T2DM) in China remain unclear.

What are the new findings?

- The T1DM and T2DM incidence rates continue to increase in China, particularly among young individuals.

- Mortality due to T1DM decreased, while mortality due to T2DM increased in males. Population aging might be associated with a substantial change in the number of deaths from 1990 to 2019.

How might these results change the focus of research or clinical practice?

- To address the increase in T2DM-related deaths due to population aging, policymakers should promote aging-related health research and implement proven cost-effective T2DM interventions.

latest national survey in China, the prevalence of diabetes increased from $0.67 \%$ in 1980 to $11.2 \%$ in 2017 considering the WHO criteria. ${ }^{12}$ China has a large population, and there were an estimated 116.4 million people living with diabetes in 2019; this figure has been projected to increase to 147.2 million in 2045 , as reported by the International Diabetes Federation (IDF). ${ }^{3}$ In 2019, over 0.8 million deaths due to diabetes among adults aged 20-79 years occurred in China. ${ }^{3}$ This 
is the highest number of deaths attributable to diabetes among all IDF regions. ${ }^{3}$ The prevalence of diabetes is important for guiding the allocation of resources for diabetes management, but prevention strategies must be implemented to decrease the incidence. Although two studies have analyzed the incidence trends of diabetes in China using the Global Burden of Disease (GBD) database, their results combined type 1 diabetes mellitus (T1DM) and type 2 diabetes mellitus (T2DM) into a single category for analysis. ${ }^{45}$ However, the epidemiological characteristics between T1DM and T2DM present significant differences. ${ }^{3}$

Meanwhile, China is one of the countries with the fastest population aging and has more people aged 65 years and older than any other country worldwide. It is estimated that by 2050, the proportion of the elderly in the total population will reach approximately $25 \% .^{6}$ The health needs of the elderly in China have brought unprecedented severe challenges to the national medical and social care system. ${ }^{6}$ To our knowledge, systematic analyses of diabetes in the population aging over a long time period in China are absent in the published literature, which has restricted policymakers from developing data-driven changes to the healthcare system to meet the growing health needs of the elderly population.

To understand and control the burden of diabetes, it is necessary to examine the trends in the incidence of and mortality due to T1DM and T2DM. China has experienced rapid aging spread, healthcare reform, and socioeconomic development. All these changes may have different effects on the incidence and mortality of different age groups. Therefore, we examined the trends of the incidence and mortality in each 5-year age group stratified by T1DM and T2DM separately over three decades. We further analyzed the impact of population aging on diabetes mortality and assessed how mortality changes affect the impact of population aging in China from 1990 to 2019.

\section{RESEARCH DESIGN AND METHODS}

\section{Data source}

The incidence and mortality rates of diabetes were derived from the GBD Study 2019, which comprised a comprehensive assessment of the incidence, prevalence, and years lived with disability for 369 morbidities in 204 countries and territories from 1990 to $2019 .{ }^{78}$ Details regarding the methodology used in the GBD 2019 study have been explained in previous studies and are presented in the online supplement. ${ }^{78}$ The incidence of and mortality due to T1DM and T2DM for all ages in China was age standardized based on the GBD 2019 age-standardized global population. ${ }^{7}$ The original data used in the GBD 2019 were obtained mainly from the Cause of Death Reporting System of the Chinese Center for Disease Control and Prevention, Disease Surveillance Points and the Maternal and Child Surveillance System, which are considered to be nationally representative. ${ }^{7}$

\section{Definition of T1DM and T2DM}

Diabetes was divided into T1DM and T2DM in the GBD study. Overall diabetes mellitus was defined as a fasting plasma glucose level $\leq 126 \mathrm{mg} / \mathrm{dL}(7 \mathrm{mmol} / \mathrm{L})$, treatment with diabetes drugs or insulin, or a diagnosis by a physician for persons aged $<15$ years that was recorded in a diabetes registry or hospital record. ${ }^{7}$ T1DM was defined as diagnosis by a physician that was recorded in a diabetes registry or hospital record. ${ }^{7}$ T2DM was calculated by subtracting the estimates of T1DM from the estimates of overall diabetes mellitus for each age, sex, and location group from 1990 to $2019{ }^{7}$

\section{Joinpoint regression analysis}

The identification of time trend changes is key in the analysis of incidence and mortality rates. These changes can be described by joinpoint regression analysis. In this study, logarithmic transformation was performed for the rates, and a binomial approximation method was used to calculate the SE. To determine the magnitude of the changes in the time trends of diabetes incidence and mortality, joinpoint regression analysis was used to evaluate the average annual percent change (AAPC) and the corresponding $95 \% \mathrm{CI}^{9}{ }^{9}$ The AAPC was calculated using the geometrically weighted average of the various annual percentage change values in the regression analysis. ${ }^{10}$ This analysis was performed using Joint Command Line V.4.5.0.1 joinpoint software provided by the United States National Cancer Institute.

\section{Age-period-cohort analysis}

To assess risks in the population in a particular year and the accumulation of health risks since birth, we used the age-period-cohort model. This model allows analysis of the independent effects of age, period, and cohort on temporal trends of diabetes incidence and mortality. The age-period-cohort model provides a useful parametric framework that complements standard nonparametric descriptive methods. In this model, the collected data were stratified into successive 5-year age groups and consecutive 5-year periods. In the age-period-cohort intrinsic estimator model, the age-specific rates were appropriately recoded into successive 5-year age groups $(0-4,5-9, \ldots, 70-74)$, consecutive 5 -year periods from 1994 to 2019 , and corresponding consecutive 5 -year birth cohort groups (1912-1916, 1920-1924, ..., 2015-2019) to estimate net age, period, and cohort effects on the incidence of and mortality due to diabetes. The age-period-cohort analysis with the intrinsic estimator method provided estimated coefficients for the age, period, and cohort effects. These coefficients were transformed into exponential values $\left[\exp (\right.$ coef. $\left.)=\mathrm{e}^{\text {coef. }}\right]$ that represent the incidence relative risk (RR) in a particular age, period, or birth cohort relative to the average level of all ages, periods, or birth cohorts combined. Age-period-cohort analysis was performed using STATA 15.0 software (StataCorp, College Station, TX, USA). 
(A) T1DM

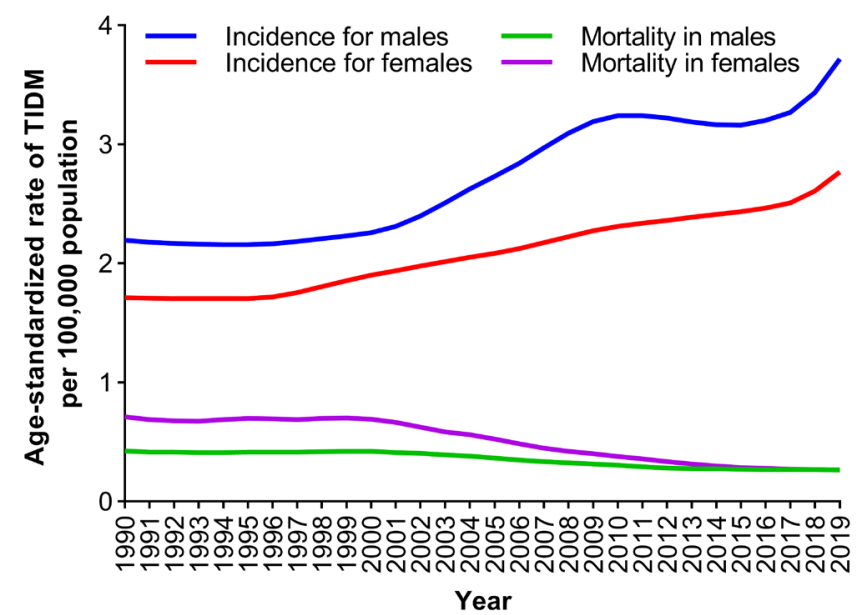

(B) T2DM

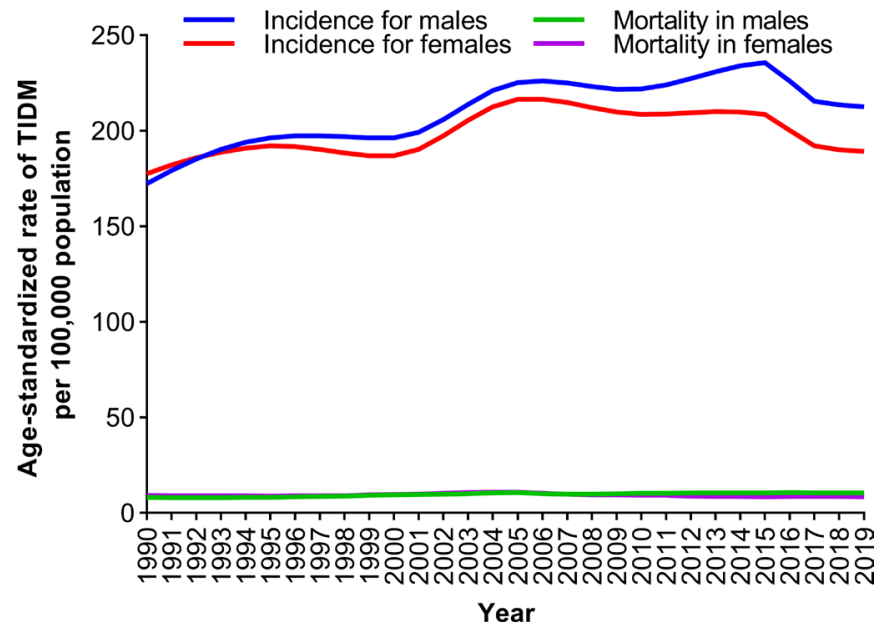

Figure 1 Trends in the age-standardized incidence and mortality rates of T1DM (A) and T2DM (B) by sex from 1990 to 2019 .

\section{Decomposition method}

A recently developed decomposition method that overcomes the sensitivity to the choice of decomposition order and the choice of reference group by calculating the contributions of population growth, population aging, and change in mortality rate is based on the following formulas ${ }^{11}$ :

$$
\begin{gathered}
M_{p}=\sum_{i=1}^{20}\left(N_{2}-N_{1}\right) s_{i 1} m_{i 1} \\
M_{a}=\sum_{i=1}^{20} N_{1}\left(s_{i 2}-s_{i 1}\right) m_{i 1} \\
M_{m}=\sum_{i=1}^{20} N_{1} s_{i 1}\left(m_{i 2}-m_{i 1}\right) \\
I_{p a}=\sum_{i=1}^{20}\left(N_{2}-N_{1}\right)\left(s_{i 2}-s_{i 1}\right) m_{i 1} \\
I_{p m}=\sum_{i=1}^{20}\left(N_{2}-N_{1}\right) s_{i 1}\left(m_{i 2}-m_{i 1}\right) \\
I_{a m}=\sum_{i=1}^{20} N_{1}\left(s_{i 2}-s_{i 1}\right)\left(m_{i 2}-m_{i 1}\right) \\
I_{p a m}=\sum_{i=1}^{20}\left(N_{2}-N_{1}\right)\left(s_{i 2}-s_{i 1}\right)\left(m_{i 2}-m_{i 1}\right)
\end{gathered}
$$

where $M_{a}, M_{p}$, and $M_{m}$ indicate the main effects of population aging, population growth, and the change in mortality rate, respectively; $\mathrm{I}_{\mathrm{pa}}, \mathrm{I}_{\mathrm{pm}}, \mathrm{I}_{\mathrm{am}}$, and $\mathrm{I}_{\mathrm{pam}}$ denote the two-way and three-way interactions of the three components; $\mathrm{m}_{\mathrm{ij}}$ and $\mathrm{s}_{\mathrm{ij}}$ denote the age-specific mortality rate and proportion of the population, respectively, for the $i$ th age group in the $j$ th year $(i=1,2, \ldots, 20 ; j=1,2)$; and $\mathrm{N}_{1}$ and $\mathrm{N}_{2}$ represent the population sizes for group 1 and group 2, respectively. The change in the number of deaths can then be attributed to population aging (A), population growth (P), and changes in age-specific mortality rates $(\mathrm{M})$ as follows:

$$
\begin{aligned}
A & =M_{a}+I_{a m}+I_{p a}+I_{p a m} \\
P & =M_{p}+I_{p m}+I_{p a}+I_{p a m} \\
M & =M_{m}+I_{p m}+I_{a m}+I_{p a m}
\end{aligned}
$$

\section{RESULTS}

\section{Descriptive analysis}

Trends in the age-standardized incidence rates (ASIRs) and age-standardized mortality rates (ASMRs) of T1DM and T2DM in males and females from 1990 to 2019 are depicted in figure 1. The ASIRs of T1DM and T2DM showed fluctuating increases from 1990 to 2019 among males and females. In addition, the ASMRs of T1DM and T2DM in males and females remained at low levels and showed downward trends from 1990 to 2019 (except T2DM in males). The number of incident cases and deaths due to T1DM and T2DM are presented in online supplemental table 1 . The incident case and death numbers of total diabetes increased by $96.0 \%$ and $146.7 \%$ respectively.

\section{Joinpoint regression analysis}

Table 1 shows the AAPCs in the incidence of and mortality due to T1DM and T2DM for both males and females in China from 1990 to 2019. The ASIRs of T1DM increased in males and females, but the ASMRs of T1DM decreased in males and females over the last three decades. For agespecific rates, the incidence increased in all age groups in males and females, and mortality decreased for all age groups in males and females during the same period.

The ASIRs of T2DM increased in males and females, and the ASMRs of T2DM increased in males but declined in females from 1990 to 2019. For age-specific rates, the incidence increased in most age groups (from age group $15-19$ to $\geq 70$ years), excluding the $45-49,50-54,55-59$, and 60-64 age groups in males and females. Mortality in males significantly increased in the 25-29 and 60 years and older age groups. Mortality in females decreased in almost all age groups, excluding the 70-year-old and older age group during the 1990-2019 period.

\section{Age-period-cohort analysis}

Figure 2 was plotted to reflect the age, period, and cohort effects based on the RR of incidence (online supplemental table 2). After controlling for period and cohort 
Table 1 Average annual percent changes (AAPCs) in incidence of and mortality due to T1DM and T2DM, 1990-2019

\begin{tabular}{|c|c|c|c|c|}
\hline \multirow{2}{*}{$\begin{array}{l}\text { Age group } \\
\text { (year) }\end{array}$} & \multicolumn{2}{|c|}{ AAPC in incidence, $\%(95 \% \mathrm{Cl})$} & \multicolumn{2}{|c|}{ AAPC in mortality, \% (95\% CI) } \\
\hline & Males & Females & Males & Females \\
\hline \multicolumn{5}{|l|}{ T1DM } \\
\hline ASR & $2.01(1.78 \text { to } 2.23)^{\star}$ & $1.7(1.61 \text { to } 1.8)^{*}$ & $-1.96(-2.22 \text { to }-1.71)^{\star}$ & $-4.02(-4.48 \text { to }-3.57)^{*}$ \\
\hline$<5$ & $0.91(0.59 \text { to } 1.22)^{\star}$ & $0.24(-0.14$ to 0.62$)$ & $-5.8(-6.15 \text { to }-5.45)^{\star}$ & $-7.27(-7.75 \text { to }-6.8)^{\star}$ \\
\hline $5-9$ & $0.78(0.51 \text { to } 1.06)^{\star}$ & $0.65(0.35 \text { to } 0.95)^{\star}$ & $-3.73(-4.07 \text { to }-3.38)^{*}$ & $-5.41(-6.14 \text { to }-4.69)^{*}$ \\
\hline $10-14$ & $1.24(1.05 \text { to } 1.43)^{\star}$ & $1.56(1.43 \text { to } 1.68)^{*}$ & $-3(-3.3 \text { to }-2.7)^{\star}$ & $-4.63(-5.28 \text { to }-3.97)^{\star}$ \\
\hline $15-19$ & $2.28(1.83 \text { to } 2.73)^{\star}$ & $3.03(2.64 \text { to } 3.42)^{*}$ & $-2.9(-3.23 \text { to }-2.57)^{*}$ & $-3.62(-4.08 \text { to }-3.15)^{*}$ \\
\hline 20-24 & $3.16(2.65 \text { to } 3.68)^{\star}$ & $3.67(3.2 \text { to } 4.14)^{\star}$ & $-1.81(-2.19 \text { to }-1.42)^{*}$ & $-3.39(-4.03 \text { to }-2.76)^{*}$ \\
\hline $25-29$ & $3.29(2.8 \text { to } 3.77)^{\star}$ & $3.39(3 \text { to } 3.78)^{\star}$ & $-0.85(-1.04 \text { to }-0.67)^{\star}$ & $-4.19(-5.2 \text { to }-3.18)^{*}$ \\
\hline $30-34$ & $3.07(2.58 \text { to } 3.56)^{\star}$ & $2.81(2.47 \text { to } 3.16)^{\star}$ & $-1.29(-1.58 \text { to }-1)^{\star}$ & $-4.72(-5.63 \text { to }-3.8)^{\star}$ \\
\hline $35-39$ & $3(2.54 \text { to } 3.47)^{\star}$ & $2.64(2.32 \text { to } 2.97)^{\star}$ & $-1.57(-1.91 \text { to }-1.23)^{\star}$ & $-4.37(-4.92 \text { to }-3.82)^{*}$ \\
\hline $40-44$ & $2.88(2.44 \text { to } 3.31)^{\star}$ & $2.45(2.14 \text { to } 2.77)^{\star}$ & $-1.66(-1.93 \text { to }-1.39)^{\star}$ & $-4.13(-4.57 \text { to }-3.69)^{\star}$ \\
\hline $45-49$ & $2.72(2.34 \text { to } 3.09)^{\star}$ & $2.19(1.9 \text { to } 2.49)^{\star}$ & $-1.72(-1.98 \text { to }-1.45)^{*}$ & $-5.06(-5.76 \text { to }-4.37)^{\star}$ \\
\hline $50-54$ & $2.66(2.34 \text { to } 2.98)^{\star}$ & $2.08(1.8 \text { to } 2.35)^{\star}$ & $-2.25(-2.58 \text { to }-1.92)^{\star}$ & $-4.75(-5.28 \text { to }-4.23)^{*}$ \\
\hline $55-59$ & $2.72(2.42 \text { to } 3.02)^{\star}$ & $2.2(1.94 \text { to } 2.47)^{\star}$ & $-2.5(-2.91 \text { to }-2.09)^{\star}$ & $-4.32(-4.78 \text { to }-3.86)^{*}$ \\
\hline $60-64$ & $2.83(2.57 \text { to } 3.1)^{\star}$ & $2.37(2.09 \text { to } 2.65)^{*}$ & $-1.84(-2.13 \text { to }-1.56)^{\star}$ & $-4.09(-4.42 \text { to }-3.76)^{\star}$ \\
\hline $65-69$ & $2.96(2.71 \text { to } 3.21)^{\star}$ & $2.57(2.26 \text { to } 2.87)^{\star}$ & $-1.85(-2.22 \text { to }-1.48)^{*}$ & $-3.5(-3.97 \text { to }-3.04)^{\star}$ \\
\hline$\geq 70$ & $3.13(2.86 \text { to } 3.4)^{\star}$ & $2.76(2.4 \text { to } 3.11)^{\star}$ & $-1.27(-1.55 \text { to }-0.99)^{\star}$ & $-2.42(-2.87 \text { to }-1.97)^{\star}$ \\
\hline \multicolumn{5}{|l|}{ T2DM } \\
\hline ASR & $0.81(0.62 \text { to } 0.99)^{\star}$ & $0.37(0.16 \text { to } 0.58)^{*}$ & $1.06(0.87 \text { to } 1.25)^{\star}$ & $-0.24(-0.54$ to 0.07$)$ \\
\hline $15-19$ & $4.46(3.62 \text { to } 5.31)^{\star}$ & $3.59(2.79 \text { to } 4.4)^{\star}$ & $-2.31(-2.77 \text { to }-1.85)^{\star}$ & $-1.71(-2.18 \text { to }-1.23)^{\star}$ \\
\hline 20-24 & $3.57(3.03 \text { to } 4.11)^{\star}$ & $2.78(2.27 \text { to } 3.29)^{*}$ & $-0.48(-0.88 \text { to }-0.09)^{\star}$ & $-2(-2.69 \text { to }-1.31)^{\star}$ \\
\hline $25-29$ & $1.79(1.49 \text { to } 2.1)^{\star}$ & $0.92(0.73 \text { to } 1.11)^{\star}$ & $0.82(0.63 \text { to } 1.01)^{\star}$ & $-2.36(-3.25 \text { to }-1.46)^{*}$ \\
\hline $30-34$ & $1.3(1.01 \text { to } 1.58)^{\star}$ & $0.36(0.17 \text { to } 0.56)^{\star}$ & $0(-0.36$ to 0.36$)$ & $-2.52(-3.28 \text { to }-1.77)^{\star}$ \\
\hline $35-39$ & $1.31(1.03 \text { to } 1.58)^{\star}$ & $0.37(0.19 \text { to } 0.54)^{*}$ & $-0.41(-0.85$ to 0.04$)$ & $-2.3(-2.78 \text { to }-1.82)^{\star}$ \\
\hline $40-44$ & $0.6(0.36 \text { to } 0.84)^{\star}$ & $0.02(-0.14$ to 0.18$)$ & $-0.15(-0.48$ to 0.18$)$ & $-2.01(-2.37 \text { to }-1.65)^{\star}$ \\
\hline $45-49$ & $-0.36(-0.71 \text { to }-0.01)^{*}$ & $-0.25(-0.41 \text { to }-0.09)^{*}$ & $-0.05(-0.32$ to 0.22$)$ & $-3.21(-3.83 \text { to }-2.59)^{*}$ \\
\hline $50-54$ & $-0.63(-1.05 \text { to }-0.21)^{\star}$ & $-0.27(-0.51 \text { to }-0.02)^{\star}$ & $-0.26(-0.52$ to 0$)$ & $-2.75(-3.31 \text { to }-2.2)^{\star}$ \\
\hline $55-59$ & $-0.4(-0.85$ to 0.06$)$ & $-0.18(-0.62$ to 0.26$)$ & $-0.41(-0.67 \text { to }-0.16)^{*}$ & $-2.21(-2.78 \text { to }-1.65)^{\star}$ \\
\hline $60-64$ & $-0.15(-0.67$ to 0.38$)$ & $0(-0.51$ to 0.51$)$ & $0.27(0.09 \text { to } 0.45)^{\star}$ & $-1.78(-2.09 \text { to }-1.47)^{\star}$ \\
\hline $65-69$ & $0.02(-0.64$ to 0.67$)$ & $0.41(-0.08$ to 0.9$)$ & $0.27(0.02 \text { to } 0.52)^{\star}$ & $-0.99(-1.35 \text { to }-0.63)^{*}$ \\
\hline$\geq 70$ & $0.33(-0.15$ to 0.82$)$ & $0.04(-0.37$ to 0.44$)$ & $1.62(1.41 \text { to } 1.82)^{\star}$ & $0.8(0.5 \text { to } 1.09)^{*}$ \\
\hline
\end{tabular}

*Indicates a $p$ value $<0.05$.

ASR, age-standardized rate.

effects, the net age effect on T1DM showed that the RR of incidence significantly increased among the $5-9,10-14$, $15-19$, and $20-24$ age groups in males and the $5-9$ and 10-14 age groups in females; the RR of mortality significantly increased among the $40-44$ age group in males and the 65-69 age group in females (online supplemental table 3). For T2DM, the RR of incidence significantly increased with advancing age (from 15 to 19 to $45-49$ in males and from 15 to 19 to 50-54 in females) but slightly decreased in the older age groups. A significantly increased RR of mortality was observed in the 50-year-old and older groups among both males and females (online supplemental table 3).
During the period of observation, the RR of T1DM incidence increased, and the RR of T1DM mortality decreased over time among both males and females, but the changes were nonsignificant. For T2DM, the RR of incidence significantly increased over time; the highest RRs were observed in 2014 among both males and females. However, the RR of T2DM mortality increased over time, but the change was nonsignificant.

No significant RRs of T1DM incidence and mortality were observed among either males or females for the birth cohort effect. The cohort effect showed that the T2DM incidence risk significantly increased from the 1920-1924 to 1945-1949 birth cohort in both males and 

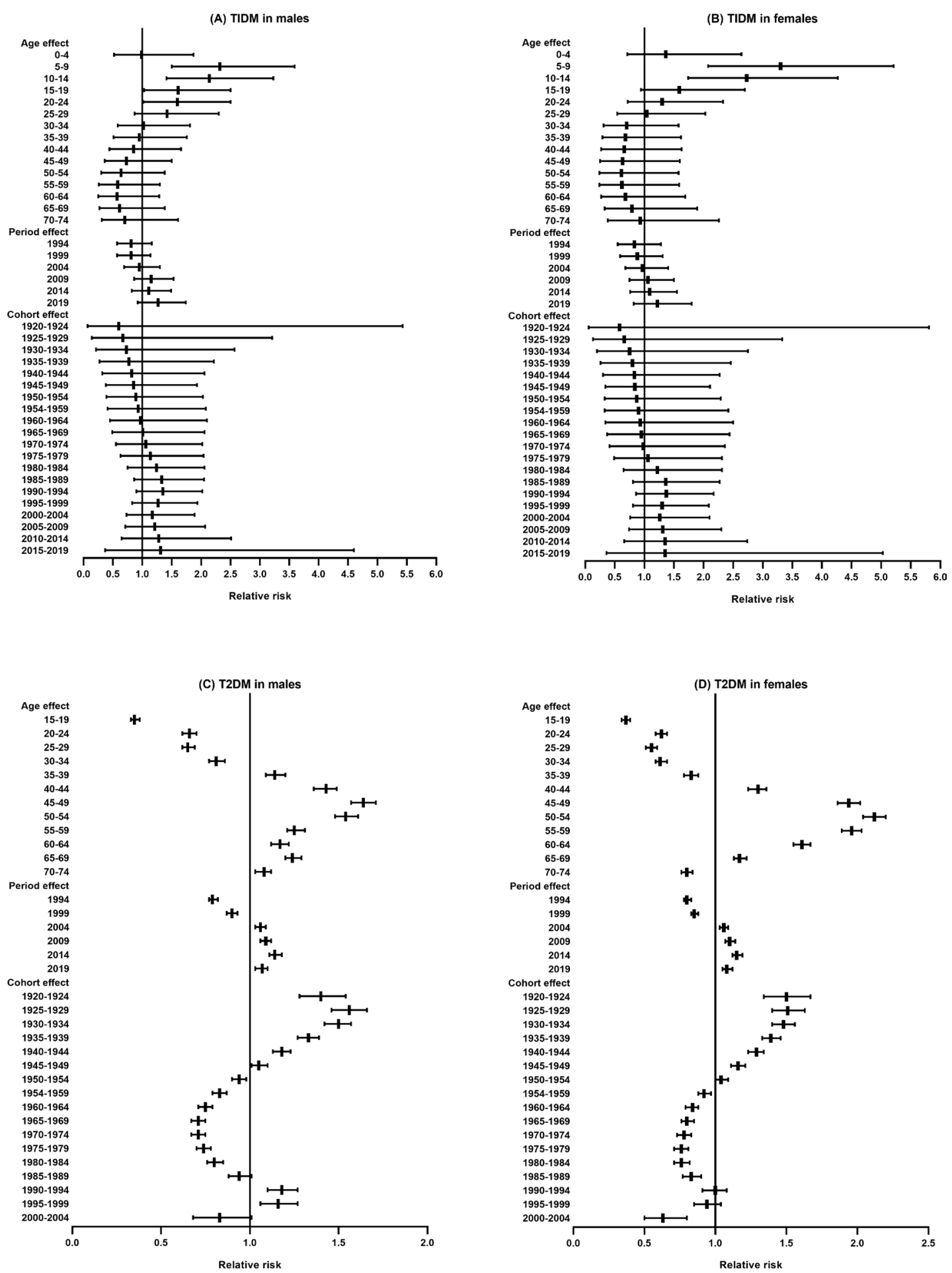

Figure 2 Relative risks of T1DM and T2DM incidence in China from 1990 to 2019 due to age, period, and cohort effects.

females and from the 1990-1994 to 1995-1999 birth cohort in males; the mortality risk significantly increased from the 1920-1924 to 1940-1944 birth cohort in both males and females and in the 1945-1949 birth cohort in females.

\section{Decomposition method}

Using 1990 as the baseline, the increase in the number of T1DM and T2DM deaths attributed to population aging and population growth increased gradually from 1991 to 2019 among both males and females (figure 3 and online supplemental table 4). Between 1990 and 2019, the change in the mortality rate was associated with a decreased number of deaths due to T1DM in both males and females and T2DM in females, while it was associated with an increased number of deaths due to T2DM in males.

The proportion of deaths attributed to population change increased steadily between 1991 and 2019 for 
(A) T1DM in males

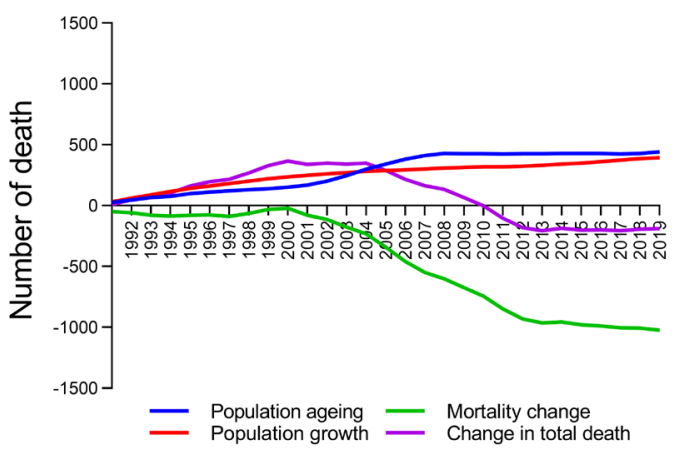

(C) T2DM in males

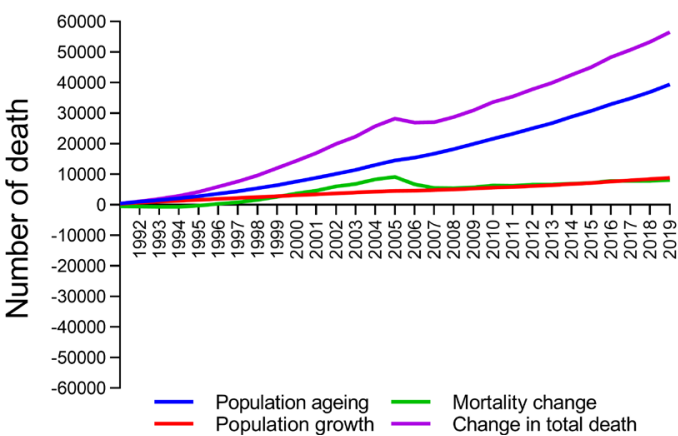

(B) T1DM in females

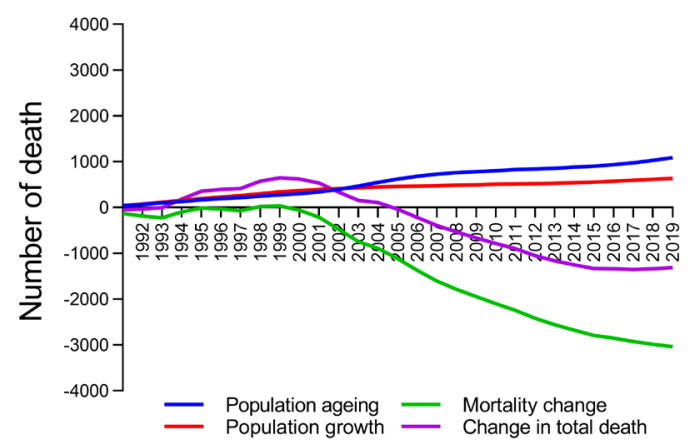

(D) T2DM in females

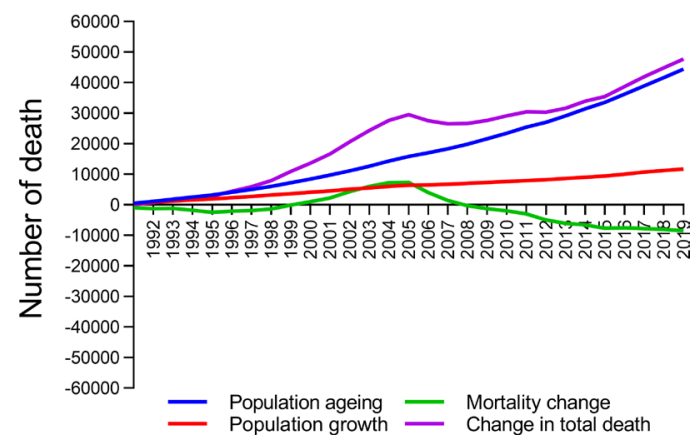

Figure 3 Changes in the number of T1DM-related and T2DM-related deaths associated with population aging, population growth, and changes in mortality rates from 1990 to 2019. Note: The decomposition was conducted using the number of deaths in 1990 as the reference for each year.

T1DM and T2DM among both males and females (figure 4). The attributed proportion increased more sharply in the T2DM group than in the T1DM group. These patterns were similar in both males and females. The attributed proportions among males were $18.85 \%$ for T1DM and $148.21 \%$ for T2DM between 1990 and

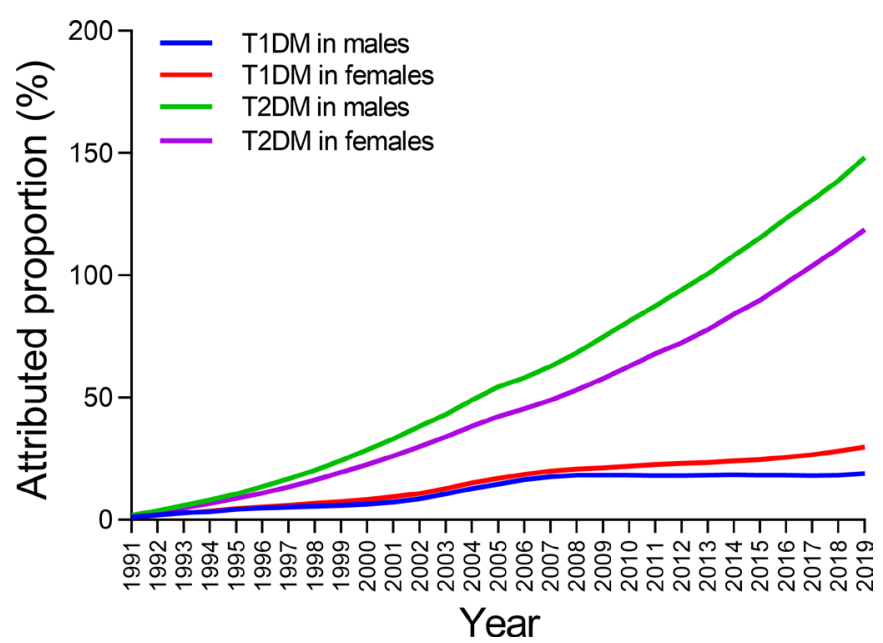

Figure 4 Proportions of T1DM and T2DM deaths associated with population aging by sex, 1990-2019. Note: The decomposition analysis was conducted using the number of deaths in 1990 as the reference. The attributed proportion of deaths was calculated as the number of deaths attributed to population aging divided by total deaths in $1990 \times 100 \%$.
2019 (figure 4). The corresponding numbers for females were $29.80 \%$ and $118.82 \%$, respectively (figure 4 ).

\section{DISCUSSION}

The present study used longitudinal data from the GBD 2019 to investigate secular incidence and mortality trends, the age-period-cohort effect, and the population aging effect on T1DM and T2DM mortality in China from 1990 to 2019. Mortality due to T1DM decreased in males and females, and mortality due to T2DM increased in males, while the T1DM and T2DM incidence increased in both males and females during the last three decades in China. This study provides a comprehensive estimate of the health impact of population aging, which might be associated with an increase of 86,000 deaths due to diabetes between 1990 and 2019. T2DM accounted for the largest number of deaths attributed to increases in population age among both males and females. In addition, the increase in deaths related to population aging between 1990 and 2019 was outweighed by the decrease in deaths attributed to mortality reduction in T1DM among both males and females.

This study found that the incidence of T1DM and T2DM has continued to increase in both males and females. Over the past three decades, Chinese society has experienced rapid development, and changes in population structures and lifestyles have had significant impacts on public health. ${ }^{12}$ Although the burden of communicable 
diseases is declining rapidly, the burden of noncommunicable diseases, such as diabetes, is steadily increasing due to individual behaviors and practices. A previous study found that mortality rates due to diabetes in all age groups had increased in China. ${ }^{4}$ This is inconsistent with our results; the difference may be explained by undistinguished diabetes type or sex or different observation period durations. In the current study, the reduction in diabetes may be due to policies such as Healthy China 2030, and long-term plans for the prevention and treatment of chronic diseases (2017-2025) have been established. The continued increase in T2DM-related mortality in males is worthy of attention. Men's health outcomes are generally poorer than women's, mainly because women are more responsive to health information and are better at seeking healthcare and practicing primary prevention than men. ${ }^{13}$

The current study also found that the incidence of T2DM has increased rapidly among the young population. Unlike that in the Western population, diabetes in China has been characterized by rapid increases in recent years, with relatively early disease onset and low rates of diabetes awareness and treatment. Compared with the Western population, the prevalence of diabetes in adults has increased rapidly in China in recent years, with an earlier onset and lower rates of awareness and treatment. ${ }^{14}$ In addition, a recent cohort study found that a younger age at onset of diabetes was significantly associated with a higher risk of subsequent dementia. ${ }^{15}$ Another prospective cohort study found that the risk of coronary heart disease in young women with new-onset diabetes was increased tenfold. ${ }^{16}$ Thus, health education and interventions targeting diabetes need to be implemented among young individuals in China.

The age effect on the incidence of T1DM was concentrated in children aged 5-14 years, while the risk of T2DM was concentrated in adults aged 45-54 years, consistent with previous studies. ${ }^{3}$ The effect of age on mortality due to T2DM significantly increased after 50 years of age in both males and females, and China's aging population may exacerbate this situation. ${ }^{17}$ Previous studies have shown that compared with younger patients, elderly patients with diabetes have a higher risk of diabetesassociated mortality, and diabetic complications are more common in elderly individuals. ${ }^{18}$ All these factors may affect the net age effect on T2DM mortality, which substantially increased with increasing age.

The period effect is usually influenced by a complex set of historical events and environmental factors. This study reported that the incidence of T2DM significantly increased since 2004. Our findings were consistent with many studies on the increasing prevalence of diabetes in China over the past decades. ${ }^{12} \mathrm{~A}$ high-energy/high-fat diet and sedentary behavior are reported to be the main causes of the expanding diabetes epidemic in China. ${ }^{19}$ The trend of the incidence of diabetes attributable to a high body mass index from 1990 to 2017 was also reported in a previous study. ${ }^{5}$ The obesity epidemic could also be attributed to the increasing incidence of diabetes in China in the past 30 years. The increase in the incidence may also be partially explained by the new diagnostic criteria, with reduced cut-off points for blood glucose and the addition of glycated hemoglobin. However, it is worth noting that the period effects on the T1DM incidence and T1DM and T2DM mortality were nonsignificant in both males and females.

The birth cohort effect reflects the characteristics of each generation and considers risk factors and exposures to environmental factors present in early life. The cohort effect on the incidence of and mortality due to T2DM led to a significantly increased risk in the earlier birth cohorts. The possible reason is that the later birth cohorts received better education and had a greater awareness of health and disease prevention than the earlier birth cohorts. ${ }^{20}$ Notably, the RR of T2DM incidence was significantly increased in the 1990-1994 to 1995-1999 birth cohorts among males. Some studies have reported that chemical exposure and environmental pollutants are associated with an increased risk of diabetes mellitus. ${ }^{21} 22$ China underwent rapid industrialization in the 1990s, and the 1990-1994 to 1995-1999 birth cohorts might have had a higher risk of diabetes due to increased exposures to chemicals and highly accessible ultra-processed foods.

Previous studies have reported that population aging is associated with increased numbers of deaths from ischemic heart disease, chronic kidney disease, and cardiovascular disease worldwide, similar to diabetes in China in this study. ${ }^{1123}$ In addition, we assessed the extent to which changes in the mortality rate reduced or increased the number of deaths associated with population aging and explored the importance of preventive efforts to reduce age-specific mortality. The increase in T1DM-related deaths related to population aging was outweighed by the decrease in deaths attributed to mortality rate reductions between 1990 and 2019. Such results may reflect the success of the initiation of disease prevention and health promotion efforts. Notably, the change in the mortality rate was associated with an increase in the number of deaths due to T2DM among males despite being associated with a decrease in the number of deaths among females. This study provides valuable data and insights for guiding health policy-making and health system reform in China.

However, a number of important limitations should also be noted. First, as the data for this study were derived from the GBD 2019, all the general limitations ascribed to that study's methodologies also apply here. ${ }^{7}$ Second, our study has an ecological fallacy and unique limitations associated with the age-period-cohort model (including the identifiability problem and uncertainty principle). Several potential cofounders, such as the impact of obesity and the increase in metabolic comorbidities during the same time period, should be considered when evaluating the effect of the age-period-cohort analysis. Third, the decomposition method used in this study 
considers only population growth, population aging, and change in mortality and thus ignores any heterogeneity in other factors related to changes in total mortality. Population aging can be caused by decreasing fertility and by increasing life expectancy. ${ }^{11}$ The increased access to medical services may prolong the survival of patients with diabetes. In addition, diagnosis at younger ages may play a role as a confounding variable. The method used in this study does not explore these mechanisms of population aging. Thus, the results need to be interpreted with caution.

\section{CONCLUSIONS}

This study showed that mortality due to T1DM decreased in males and females, while mortality due to T2DM increased in males. The incidence of T1DM and T2DM increased from 1990 to 2019. Younger individuals had the largest annual percent increases in the incidence of T1DM and T2DM. Thus, timely programs aiming to reduce the potential burden on youth should be conducted. Population aging has likely driven the continued increases in total deaths due to T2DM during the last three decades. To respond to the increase in the number of deaths related to population aging in T2DM, policymakers should invest in aging-related health research and implement proven, cost-effective interventions targeting T2DM.

\section{Author affiliations}

${ }^{1}$ Department of Endocrinology and Metabolism, The Institute of Endocrinology, NHC Key Laboratory of Diagnosis and Treatment of Thyroid Diseases, The First Hospital of China Medical University, Shenyang, Liaoning, China

${ }^{2}$ Department of Chemical Engineering and Materials Science, Stevens Institute of Technology, Hoboken, New Jersey, USA

\section{Acknowledgements The authors acknowledge the IHME for providing the data} for this article.

Contributors YL contributed to the data acquisition, analysis, and interpretation and drafted and critically reviewed the manuscript for intellectual content. CG contributed to the data analysis. YC conceived and designed the study. All authors reviewed and approved the final version of the manuscript. YL and YC are the guarantors of this work and, as such, had full access to all the data in the study and takes responsibility for the integrity of the data and the accuracy of the data analysis.

Funding This work was supported by the National Natural Science Foundation of China (Grant No. 82000753) and the China Medical University Youth Support Program (Grant No. QGZD2018036).

Disclaimer The funding sources had no role in the study design, data analysis, interpretation, or decision to submit for publication.

Competing interests None declared.

Patient consent for publication Not applicable.

Ethics approval The Institutional Review Board of the First Hospital of China Medical University determined that this study did not require approval because it used publicly available data.

Provenance and peer review Not commissioned; externally peer reviewed.

Data availability statement Data are available in a public, open access repository. The datasets generated and/or analyzed during the current study are available in the http://ghdx.healthdata.org/gbd-results-tool.

Supplemental material This content has been supplied by the author(s). It has not been vetted by BMJ Publishing Group Limited (BMJ) and may not have been peer-reviewed. Any opinions or recommendations discussed are solely those of the author(s) and are not endorsed by BMJ. BMJ disclaims all liability and responsibility arising from any reliance placed on the content. Where the content includes any translated material, BMJ does not warrant the accuracy and reliability of the translations (including but not limited to local regulations, clinical guidelines, terminology, drug names and drug dosages), and is not responsible for any error and/or omissions arising from translation and adaptation or otherwise.

Open access This is an open access article distributed in accordance with the Creative Commons Attribution Non Commercial (CC BY-NC 4.0) license, which permits others to distribute, remix, adapt, build upon this work non-commercially, and license their derivative works on different terms, provided the original work is properly cited, appropriate credit is given, any changes made indicated, and the use is non-commercial. See: http://creativecommons.org/licenses/by-nc/4.0/.

ORCID iD

Yongze Li http://orcid.org/0000-0001-8782-3314

\section{REFERENCES}

1 Zhong XL. Diabetes mellitus survey in China. Chin Med $J$ 1982;95:423-30.

2 Li Y, Teng D, Shi X, et al. Prevalence of diabetes recorded in mainland China using 2018 diagnostic criteria from the American Diabetes Association: national cross sectional study. BMJ 2020;95:m997.

3 International Diabetes Federation. IDF diabetes atlas. 9th edn. Brussels, Belgium: International Diabetes Federation, 2019. https:// www.diabetesatlas.org

4 Liu M, Liu S-W, Wang L-J, et al. Burden of diabetes, hyperglycaemia in China from to 2016: findings from the 1990 to 2016, global burden of disease study. Diabetes Metab 2019;45:286-93.

5 Liu X, Yu C, Wang Y, et al. Trends in the incidence and mortality of diabetes in China from 1990 to 2017: a joinpoint and age-periodcohort analysis. Int J Environ Res Public Health 2019;16:158.

6 The Lancet. Ageing in China: a ticking bomb. Lancet 2016;388:388.

7 GBD 2019 Diseases and Injuries Collaborators. Global burden of 369 diseases and injuries in 204 countries and territories, 1990-2019: a systematic analysis for the global burden of disease study 2019. Lancet 2020;396:1204-22. doi:10.1016/S0140-6736(20)30925-9

8 GBD 2019 Risk Factors Collaborators. Global burden of 87 risk factors in 204 countries and territories, 1990-2019: a systematic analysis for the global burden of disease study 2019. Lancet 2020;396:1223-49. doi:10.1016/S0140-6736(20)30752-2

$9 \mathrm{Kim} \mathrm{H-J,} \mathrm{Fay} \mathrm{MP,} \mathrm{Feuer} \mathrm{EJ,} \mathrm{et} \mathrm{al.} \mathrm{Permutation} \mathrm{tests} \mathrm{for}$ joinpoint regression with applications to cancer rates. Stat Med 2000;19:335-51.

10 Clegg LX, Hankey BF, Tiwari R, et al. Estimating average annual per cent change in trend analysis. Stat Med 2009;28:3670-82.

11 Cheng X, Yang Y, Schwebel DC, et al. Population ageing and mortality during 1990-2017: a global decomposition analysis. PLoS Med 2020;17:e1003138.

12 Yang G, Wang Y, Zeng Y, et al. Rapid health transition in China, 1990-2010: findings from the Global Burden of Disease Study 2010. The Lancet 2013;381:1987-2015.

$13 \mathrm{Hu}$ C, Jia W. Diabetes in China: epidemiology and genetic risk factors and their clinical utility in personalized medication. Diabetes 2018:67:3-11.

$14 \mathrm{Li} \mathrm{Y}$, Wang DD, Ley SH, et al. Time trends of dietary and lifestyle factors and their potential impact on diabetes burden in China. Diabetes Care 2017:40:1685-94.

15 Barbiellini Amidei C, Fayosse A, Dumurgier J, et al. Association between age at diabetes onset and subsequent risk of dementia. JAMA 2021;325:1640-9.

16 Dugani SB, Moorthy MV, Li C, et al. Association of lipid, inflammatory, and metabolic biomarkers with age at onset for incident coronary heart disease in women. JAMA Cardiol 2021;6:437-47.

17 Kanasi E, Ayilavarapu S, Jones J. The aging population: demographics and the biology of aging. Periodontol 2000 2016;72:13-18.

18 Chi M-J, Liang C-K, Lee W-J, et al. Association of new-onset diabetes mellitus in older people and mortality in Taiwan: a 10year nationwide population-based study. J Nutr Health Aging 2017:21:227-32.

19 Ministry of Public Health. Nutrition and health status among Chinese: result from the fourth China nutrition and health survey. Ministry of Public Health ed. Beijing: Ministry of Public Health, 2004. 
20 Cohen AK, Syme SL. Education: a missed opportunity for public health intervention. Am J Public Health 2013;103:997-1001.

$21 \mathrm{Li} \mathrm{Y,} \mathrm{Xu} \mathrm{L,} \mathrm{Shan} \mathrm{Z,} \mathrm{et} \mathrm{al.} \mathrm{Association} \mathrm{between} \mathrm{air} \mathrm{pollution} \mathrm{and} \mathrm{type}$ 2 diabetes: an updated review of the literature. Ther Adv Endocrinol Metab 2019;10:2042018819897046.
22 Leso V, Capitanelli I, Lops EA, et al. Occupational chemical exposure and diabetes mellitus risk. Toxicol Ind Health 2017;33:222-49.

23 Roth GA, Forouzanfar MH, Moran AE, et al. Demographic and epidemiologic drivers of global cardiovascular mortality. N Engl $J$ Med 2015;372:1333-41. 